\title{
A CLINICAL STUDY ABOUT INCIDENCE OF OCCULT MALIGNANCY IN LONGSTANDING MULTINODULAR GOITRE
}

Gopinathan Sivasankaran', Deepika', Gautam

${ }^{2}$ Assistant Professor, Department of Surgical Oncology, Father Muller Medical College, Mangalore. ${ }_{2}^{2}$ Assistant Professor, Department of Surgical Oncology, Father Muller Medical College, Mangalore. ${ }_{3}^{3}$ unior Resident, Department of Surgical Oncology, Father Muller Medical College, Mangalore.

\section{ABSTRACT}

\section{BACKGROUND}

Goitre is one of the common features of thyroid disease presentation. Most of the thyroid nodules were found accidentally by Ultrasound and clinical evaluation. Historically chances of malignancy in Multinodular Goitre was very low compared to solitary nodular goitre.

The objective of this study is to determine the incidence of occult malignancy in longstanding MNG.

\section{MATERIALS AND METHODS}

This is a prospective, observational study conducted from May 2015 - August 2017 by Department of Surgical Oncology, Father Muller Medical College Hospital, Mangalore. All the goitre patients were examined clinically and sonographically. The patient was offered surgery based on suspicious findings in Sonography and FNAC. Post-operative specimens were subjected to histopathological examination to find out the incidence and the types various malignancies.

\section{RESULTS}

Among 60 MNG cases, 8 cases (13\%) showed malignant foci. Most common type of malignancy observed was Papillary carcinoma (75\%).

\section{CONCLUSION}

Risk of malignancy is quite significant in longstanding Multinodular goitre. All the patients with Multinodular goitre need proper evaluation, adequate surgery and thorough histopathological evaluation

\section{KEYWORDS}

Multinodular Goitre, Thyroid Malignancy, Thyroidectomy.

HOW TO CITE THIS ARTICLE: Sivasankaran G, Deepika, Gautam. A clinical study about incidence of occult malignancy in longstanding multinodular goitre. J. Evolution Med. Dent. Sci. 2017;6(91):6403-6405, DOI: 10.14260/jemds/2017/1392

\section{BACKGROUND}

Goitre is one of the common ways of thyroid disease presentation. Most of the Thyroid nodules were found accidentally by Ultrasound (30-50\%) and clinical evaluation. $(1,2,3)$

The incidence of thyroid malignancy ranges from 10 to $13 \%$ (11) and incidence further increases if cases of occult carcinoma also included. The availability of effective diagnostic test increases the incidence of occult thyroid carcinoma. ${ }^{(4,5)}$

Historically chances of malignancy in MNG was very low. $(4,6,7)$ Longstanding MNG is associated with malignancy or not is a longstanding debate. But various studies reported 5 to $15 \%$ incidence of malignancy in longstanding MNG. $(6,8,9)$

'Financial or Other Competing Interest': None.

Submission 12-10-2017, Peer Review 10-11-2017,

Acceptance 18-11-2017, Published 27-11-2017.

Corresponding Author:

Dr. Gopinathan Sivasankaran,

Assistant Professor,

Department of Surgical Oncology,

Father Muller Medical College, Mangalore.

E-mail:dr.s.gopinathan@gmail.com

DOI: $10.14260 /$ jemds/2017/1392
The management of solitary nodule has been refined by FNAC, unlike MNG, in which a nodule of a carcinoma can't be differentiated clinically or radiologically amidst other benign nodules.(10,11)

Most common type of thyroid malignancy in longstanding MNG is Papillary Carcinoma. $(7,11)$

The objective of this study is to determine the incidence of occult malignancy in longstanding MNG.

\section{MATERIALS AND METHODS}

This is a prospective, observational study conducted from May 2015 - August 2017 by Department of Surgical Oncology, Father Muller Medical College Hospital, Mangalore. Most of the patients are from coastal Karnataka and Kerala. All the goitre patients were examined clinically and sonographically. Sonography shows Multinodular goitre and shows suspicious features of malignancy, subject to FNAC. FNAC shows follicular neoplasm and equivocal findings taken for Total/near total thyroidectomy.

\section{Inclusion Criteria}

A. Longstanding MNG.

B. FNAC Shows follicular neoplasm or equivocal results.

C. USG features of microcalcification, mixed echogenicity.

D. Pressure symptoms.

E. Thyrotoxicosis. 


\section{Exclusion Criteria}

FNAC-proved malignancy.

\section{RESULTS}

In this study, we had 100 patients of Goitre, of these 60 were MNG cases. Among 60 MNG patients, 52 cases (86.7\%) were female and 8 cases $(13.3 \%)$ were male with a striking female predominance. Majority of these patients were in the $3^{\text {rd }}$ and $4^{\text {th }}$ decade (Table 1 ).

The common presenting complaint was swelling in the neck. Median duration of lump was 12 months. Thyroid Sonography was done in all cases and median numbers of nodules were two and median size of nodule was $1.5 \mathrm{~cm} .20$ MNG patients showed area of microcalcification with solid and hypoechogenic areas. FNAC was performed on all cases. The FNAC showed colloid goitre in 11 cases and follicular neoplasm in 9 cases and inconclusive in 10 cases. Of these 9 follicular neoplasm cases, 2 were malignant and while among the 10 cases with an inconclusive FNAC report, 2 revealed malignant focus. Patients were offered surgery based on suspicious findings during the diagnostic workup, equivocal results from the various investigations, compressive symptoms, thyrotoxicosis and cosmesis.

In all cases, total thyroidectomy was carried out and specimens were subjected to a histopathological examination. Histopathology of the specimen revealed that 8 patients had a malignant focus and incidence of carcinoma in MNG in our study. Among the malignancy, Papillary Carcinoma was common (Table 2).

Common age groups for the presentation of carcinoma of thyroid was 41 to 50 . Among 8 patients of the MNG and carcinoma thyroid, 7 were female, 1 was male (Table 2). Among the 8 cases of MNG and carcinoma thyroid, 5 patients showed smaller than $2 \mathrm{~cm}$. None of the toxic MNG and hypothyroidism cases revealed a malignant focus.

\begin{tabular}{|c|c|c|}
\hline a. Age & Number & \% \\
\hline $0-20$ & 02 & $03.3 \%$ \\
\hline $21-30$ & 05 & $08.3 \%$ \\
\hline $31-40$ & 18 & $30.0 \%$ \\
\hline $41-50$ & 22 & $36.7 \%$ \\
\hline $51-60$ & 10 & $16.7 \%$ \\
\hline $61-70$ & 03 & $05.0 \%$ \\
\hline \multicolumn{3}{|c|}{ Table 1 - Patient Characteristics } \\
\hline
\end{tabular}

\begin{tabular}{|c|c|c|}
\hline b. Presenting Complaint & Number & $\mathbf{\%}$ \\
\hline a. Swelling in the Neck & 50 & $83.3 \%$ \\
\hline b. Hyperthyroidism & 03 & $05.0 \%$ \\
\hline c. Hypothyroidism & 02 & $03.3 \%$ \\
\hline d. Obstructive symptoms & 01 & $01.7 \%$ \\
\hline e. Others & 04 & $06.7 \%$ \\
\hline
\end{tabular}

\begin{tabular}{|c|c|c|}
\hline c. Sex & Number & \% \\
\hline Male & 08 & $13.3 \%$ \\
\hline Female & 52 & $86.7 \%$ \\
\hline \multicolumn{2}{|c|}{ Table 2 } & - Results of the Study \\
\hline
\end{tabular}

\begin{tabular}{|c|c|c|}
\hline A. Incidence of malignancy & No. & $\mathbf{\%}$ \\
\hline Benign & 52 & $86.7 \%$ \\
\hline Malignant & 08 & $13.3 \%$ \\
\hline
\end{tabular}

\begin{tabular}{|c|c|c|}
\hline B. Type of Malignancy & No. & \% \\
\hline Benign & 52 & $86.7 \%$ \\
\hline Papillary carcinoma & 06 & $10.0 \%$ \\
\hline Follicular carcinoma & 01 & $01.7 \%$ \\
\hline Hurthle cell carcinoma & 01 & $01.7 \%$ \\
\hline Medullary carcinoma & 00 & 00 \\
\hline
\end{tabular}

\begin{tabular}{|c|c|c|}
\hline C. Sex wise distribution of Malignancy & No. & $\mathbf{\%}$ \\
\hline Male & 01 & $12.5 \%$ \\
\hline Female & 07 & $87.5 \%$ \\
\hline Total & 08 & $100 \%$ \\
\hline
\end{tabular}

\begin{tabular}{|c|c|c|}
\hline $\begin{array}{c}\text { D. Age wise distribution of } \\
\text { Malignancy }\end{array}$ & No. & \% \\
\hline $0-20$ & 0 & 0 \\
\hline $21-30$ & 0 & 0 \\
\hline $31-40$ & 03 & $37.5 \%$ \\
\hline $41-50$ & 04 & $50.05 \%$ \\
\hline $51-60$ & 01 & $12.5 \%$ \\
\hline$>60$ & 00 & - \\
\hline Total & $\mathbf{0 8}$ & $\mathbf{1 0 0 \%}$ \\
\hline
\end{tabular}

\section{DISCUSSION}

MNG is defined as the palpation of multiple nodules in the enlarged thyroid gland. The risk factors for the development of MNG were Iodine deficiency, impairment of hormone synthesis, increased urinary excretion of iodine, presence of thyroid stimulating immunoglobulin.(10)

Thyroid nodules were mostly diagnosed by clinical examination and USG.(1,2,3)50.5\% of solitary nodules which are felt on palpation are actually part of the dominant Nodule in MNG. Palpation of multiple nodules hampered by the obesity, short neck and less than $1 \mathrm{~cm}$ in size in goitre. Surgery is offered mainly for cosmesis and rarely for toxicity, compressive symptoms and suspicious of malignancy.(12)

Historically, MNG compared to solitary nodule has low risk of malignancy. $(4,6,7)$ However, various studies proved MNG is also one of the risk factor for malignancy.

A study conducted by Sara Jevo(13) reported $8 \%$ of malignancy in MNG and Benhzari et al found 9.5\% Incidence of malignancy in MNG.(14,15) However, Prades et al from France, reports $12.2 \%$ incidence of malignancy in MNG.(14,16)

As per literature, most common type of malignancy in MNG was Papillary Ca.(7,1) The incidence of malignancy in MNG in our study was $13 \%$ and most common type of malignancy was papillary carcinoma, this is consistent with from Prades et al.(14)

Incidence of malignancy is high on dominant nodules in MNG. Palpation of hard, irregular, fixed thyroid gland, rapidly increasing in size, and associated with cervical lymph adenopathy, recurrent laryngeal nerve palsy and male sex.(14) 
A patient with history of neck irradiation and family history of thyroid carcinoma should make the suspicion strong.(14)

High frequency neck ultrasound and FNAC are valuable preoperative tools for evaluation of MNG for malignancy.(1)

Sonographic findings suspicious of malignancy are microcalcification, irregular nodule, complex echogenicity.

FNAC is an inexpensive and fast investigation which can be done to obtain the cellular samples.(1)Sensitivity of FNAC for diagnosing malignancy is $80-85 \%$. Negative FNAC does not rule out malignancy. ${ }^{(6,7) S o}$ USG guided FNAC of suspicious nodule is of great help.

Most common endocrine tumour is thyroid Carcinoma which accounts for $1 \%$ of malignancy. Incidence of malignancy varies in different regions of world. For the past 60 years, the incidence of thyroid carcinoma increases by 5 fold (51\%).(17)

The tumours are rare in children and increases with age and females have higher incidence.(14) Though ionising radiation, iodine deficiency and other factors have been attributed to the increase in thyroid carcinoma, these findings are inconsistent.

Previously, hormonal factors, lactation suppressive drugs and fertility medication have been implicated for the higher incidence of Thyroid cancer in females.(14)but recent studies reported that the use of hormonal therapy of fertility drugs are not associated with thyroid malignancy. $(18,19)$

The availability of more sensitive and better diagnostic tools may be responsible for the increasing incidence of thyroid cancer.

Papillary micro carcinoma was a frequent incidental finding in autopsy studies. Papillary microcarcinoma defined by size less than $10 \mathrm{~mm}$ in the greatest dimension. Untreated papillary microcarcinoma classically progresses to clinically evident Papillary thyroid carcinoma which was confirmed by various studies.(5,20)So the treatment of papillary microcarcinoma should be similar to that of conventional papillary carcinoma. ${ }^{(21)}$

\section{CONCLUSION}

Risk of malignancy is quite significant in longstanding Multinodular goitre. All the patients with Multinodular goitre need proper evaluation, adequate surgery and thorough histopathological evaluation.

\section{REFERENCES}

[1] Pang HN, Chen CM. Incidence of cancer in nodular goitres. Ann Acad Med Singapore 2007;36(4):241-3.

[2] Belfiore A, La Rosa GL, Padova G, et al. The frequency of cold thyroid nodules and thyroid malignancies in patients from an iodine-deficient area. Cancer 1987;60(12):3096-102.

[3] Mazzaferri EL, de los Santos ET, Rofagha-Keyhani S. Solitary thyroid nodule: diagnosis and management. Med Clin North Am 1988;72(5):1177-211.

[4] Memon W, Khanzada TW, Samad A, et al. Incidence of thyroid carcinoma in multi-nodular goitres. Rawal Med J 2010;35.
[5] Cerci C, Cerci SS, Eroglu E, et al. Thyroid cancer in toxic and non-toxic multinodular goitre. J Postgrad Med 2007;53(3):157-60.

[6] Gandolfi PP, Frisina A, Raffa M, et al. The incidence of thyroid carcinoma in multinodular goitre: retrospective analysis. Acta Biomed2004;75(2):114-7.

[7] Pedamallu R, Pedamallu SB, Rama Rao K, et al. Incidence of occult carcinoma in multi-nodular goitre which was diagnosed on the basis of the histopathological findings. Internet J Surg 2008;17:1.

[8] Cole WH. Incidence of carcinoma of the thyroid in nodular goitre. Semin Surg Oncol 1991;7(2):61-3.

[9] Sachmechi I, Miller E, Varatharajah R, et al. Thyroid carcinoma in the single cold nodules and in the cold nodules of multinodular goitres. Endocr Pract 2000;6(1):5-7.

[10] Abu-Eshy SA, Khan AR, Khan GM, et al. Thyroid malignancy in multinodular goitre and solitary nodule. J R Coll Surg Edinb 1995;40(5):310-2.

[11] Koh KB, Chang KW. Carcinoma in multinodular goitre. Br J Surg 1992;79(3):266-7.

[12] Tan GH, Gharib H, Reading CC. Solitary thyroid nodule. Comparison between palpation and ultrasonography. Arch Intern Med 1995;155(22):2418-23.

[13] Alagic-Smailbegovic J, Kapidzic A, Sutalo K, et al. Surgical treatment of thyroid gland disease. Med Arh 2005;59(4):241-3.

[14] ul Haq RN, Khan BA, Chaudhry IA. Prevalence of malignancy in goiter--a review of 718 thyroidectomies. J Ayub Med Coll Abbottabad 2009;21(4):134-6.

[15] Benzarti S, Miled I, Bassoumi T, et al. Thyroid surgery (356 cases): risks and complications. Rev Laryngol Otol Rhinol (Board) 2002;123(1):33-7.

[16] Prades JM, Dumollard JM, Timoshenko A, et al. Multinodular goitre: surgical management and histopathological findings. Eur Arch Otolaryngol 2002;259(4):217-21.

[17] Whelan SL, Parkin DM, Masuyer E. The patterns of cancer in five continents. IARC Sci Publ 1990;102:1523.

[18] Memon A, Darif M, Al Saleh K, et al. Epidemiology of the reproductive and hormonal factors in thyroid cancer: evidence from a case control study in the Middle East. Int J Cancer 2002;97(1):82-9.

[19] La Vecchia C, Ron E, Franceschi S, et al. A pooled analysis of the case-control studies of thyroid cancer. III.Oral contraceptives, menopausal replacement therapy and other female hormones. Cancer Causes Control 1999;10(2):157-66.

[20] Barbaro D, Simi U, Meucci G, et al. Thyroid papillary cancers: microcarcinoma and carcinoma, incidental cancers and non-incidental cancers-are they different diseases? Clin Endocrinol Oxf 2005;63(5):577-81.

[21] Kucuk NO, Tari P, Tokmak E, et al. Treatment for microcarcinoma of the thyroid-clinical experience. Clin Nucl Med 2007;32(4):279-81. 